\title{
A Novel Evaluation Method of Hydrogen Production from Coal Based on AHP and GRA-TOPSIS
}

\author{
Shuheng Zhong, ${ }^{1}$ Kangdi Yang $\mathbb{D}^{1}{ }^{1}$ and Yongji Wang ${ }^{1,2}$ \\ ${ }^{1}$ School of Energy and Mining Engineering, China University of Mining and Technology, Beijing,10083, China \\ ${ }^{2}$ China Association for Science and Technology Enterprise Innovation Service Center, Beijing,100026, China \\ Correspondence should be addressed to Kangdi Yang; 23220106@qq.com
}

Received 22 August 2021; Accepted 23 September 2021; Published 4 October 2021

Academic Editor: Gaofeng Song

Copyright (C) 2021 Shuheng Zhong et al. This is an open access article distributed under the Creative Commons Attribution License, which permits unrestricted use, distribution, and reproduction in any medium, provided the original work is properly cited.

\begin{abstract}
Coal is the cornerstone of China's energy. However, with the proposed goal of carbon peak and carbon-neutral in China, coal enterprises are in urgent need of exploring the path of transformation. Coal to hydrogen is an important way to achieve sustainable development of the coal industry. In this paper, four hydrogen production technologies, including coal gasification, coke oven gas, electrolytic water, and solar energy, are studied. A comprehensive evaluation model based on GRA-TOPSIS was constructed. The research shows that the coke oven gas is the most suitable hydrogen production technology for the transformation and development of coal enterprises. The evaluation model of hydrogen production technology in the transformation and development of coal enterprises constructed in this paper has a certain guiding effect on the technology selection of coal enterprises in the development of the hydrogen industry.
\end{abstract}

\section{Introduction}

On March 5, 2021, the government work report stated that this year China will make solid efforts to achieve a carbon peak and carbon neutrality and formulate an action plan to achieve a carbon peak by 2030. Optimizing industrial structure and energy structure is the main means to promote carbon peak and carbon-neutral in the overall realization of the carbon-neutral goal. In the past decade and for a period of time in the future, China's energy structure is still dominated by coal [1]. Under the background of China's "carbon peak by 2030" and "carbon-neutral by 2060" goals, large state-owned enterprises, especially energy enterprises, are facing the urgent need of low-carbon transformation, and hydrogen energy is one of the important directions of their transformation [2,3]. It is of great significance to realize the efficient and clean utilization of coal resources, not only for the transformation and development of enterprises but also for the acceleration of national carbon peak and carbonneutral work.
According to the 14th five-year plan, hydrogen energy has been included in the strategic development position as an important industry in the future [4]. China's hydrogen mainly comes from natural gas or coal to produce hydrogen, coke oven gas, and so on. The vast majority are blue hydrogen and gray hydrogen. The green hydrogen project is currently in the demonstration stage. With the guidance of China's policies and the implementation of a large number of hydrogen energy projects, the hydrogen energy technology continues to break through, the industrial system is gradually improved, and the development of the hydrogen energy field in China has accelerated into the industrialization stage.

Hydrogen energy can be produced from various resources, using different raw materials, methods, and technologies, including fossil fuels and renewable resources [5-7]. Meanwhile, China is rich in coal resources, and hydrogen production from coal is the main form of hydrogen production in China [8], which can significantly increase the added value of coal products [9-12]. 
However, hydrogen production technology is complex, and the transformation and development of energy enterprises often require comprehensive consideration from multiple aspects. Therefore, a comprehensive evaluation system model based on energy, economy, environment, technology, and society has been established based on the comprehensive study of hydrogen technology selection of various hydrogen production technologies. In view of the mainstream mature hydrogen production technology and the consideration of renewable energy utilization, four hydrogen production technologies including coal gasification hydrogen production, coke oven gas hydrogen production, water electrolysis hydrogen production, and solar energy hydrogen production were selected for a comprehensive evaluation, to obtain the optimal hydrogen production technology through hydrogen energy transformation and upgrading of energy enterprises. It is of great significance to the transformation and upgrading of the coal industry and coal chemical industry which take hydrogen as the breakthrough point.

\section{Literature Review}

The technical economy is the internal driving force in the development of coal industry transformation; there are many influential factors in the technology economy; the need for multiple factors and changes impacts the economy analysis [13]. Building the corresponding technical and economic evaluation model, for many factors, at the same time tries to realize the evaluation process of standardization and automation in order to facilitate the comparative analysis between evaluation results and between evaluation results and samples [14].

Deciding how to assess hydrogen production technology scientifically is a problem that needs to be handled. In general, there are two types of methods to solve this problem: (1) synthetical assessment approaches, e.g., weighted sum, analytical hierarchy process (AHP) [15], and the technique for order performance by similarity to ideal solution (TOPSIS) [16]. AHP and evidential reasoning, AHP and TOPSIS, and fuzzy synthetic evaluation are (2) the approaches based on theory of life cycle assessment $[17,18]$.

Li Yiyang established a model applicable to the evaluation system of hydrogen production technology by using the life cycle evaluation theory, which included the evaluation of material consumption, energy consumption, environment, and economy [19]. The research results showed that the comprehensive benefit of hydrogen production from biomass supercritical water gasification was the highest. Luo Bing introduced the two main methods of hydrogen production from biomass, namely, thermalization method and microbial conversion method, from the aspects of hydrogen production mechanism, technological process, existing problems, and development prospects. After comparing and understanding several hydrogen production methods, it is found that the hydrogen production technology from biomass is the most efficient and environmental protection technology, which can not only optimize the fuel structure and improve the air pollution status in China but also reduce the secondary pollution caused by the unreasonable utilization mode at present [20]. Xie Xinshuo used traditional hydrogen production technologies (gasification hydrogen production, natural gas hydrogen production, and so on) and new hydrogen production technologies (thermochemical hydrogen production, renewable energy power generation hydrogen production, biomass gasification hydrogen production, and so on) as the object; the research on its life cycle assessment shows that wind power hydrogen production technology has the best environmental protection, and nuclear thermochemical hydrogen production has the potential for large-scale application in the future [21]. Niu Jiao established an evaluation model based on an improved fuzzy evaluation method. The hydrogen production technology with the highest comprehensive benefit is natural gas steam reforming hydrogen production technology, and the hydrogen production technology with the lowest comprehensive benefit is hydrogen production by electrolysis of water [22].

The above research results are a single or multidimensional systematic evaluation of various hydrogenmaking technologies by experts and scholars, but the actual application of hydrogen-making technology in a certain field has not been fully considered. Under the current background of "carbon peak and carbon neutrality" and restricted by foreign technology, the traditional $3 \mathrm{E}$ evaluation model cannot better reflect the influence of technical factors and social factors [23]. The olefin industry is evaluated based on the $3 \mathrm{E}$ model, but it does not reflect the impact of its social and technological factors [24]. Hence, coal enterprises urgently need a set of scientific, comprehensive, and targeted evaluation indicators and evaluation methods. Therefore, this article adds two dimensions of technology and society to the analysis of the $3 \mathrm{E}$ model, that is, comprehensive analysis of each hydrogen production technology from the five dimensions of energy, economy, environment, technology, and society and combines with a specific mining group for practical applications.

\section{Impact Analysis and Model Construction}

3.1. Impact Analysis. Considering the complexity of hydrogen production technology, in this section, we provide theoretical support for the model establishment in Section 3.2 by analyzing the influencing factors at five different levels of hydrogen production technology.

The influence of hydrogen technology in the energy dimension is mainly reflected in the influence of resource suitability, hydrogen efficiency, and the proportion of endenergy consumption change and the proportion of clean energy consumption increase. Therefore, the applicability of resources, hydrogen efficiency, and the proportion of changes in end-use energy consumption are introduced as indicators in energy.

Compared with other energy sources, the cost gap between various types of hydrogen technology is large. At the same time, in order to simplify the calculation, the investment cost of hydrogen plant construction is used as a 
separate index. Therefore, the following economic influencing factors were used to establish the indicator: (1) the cost per unit of hydrogen production; (2) investment costs; (3) gross enterprise product.

In the environmental impact of the main performance in the "three wastes," that is, "emissions, waste residue, waste water," the most significant environmental impact is the emission of exhaust gases; therefore, in the environmental impact factor subsystem, $\mathrm{CO}_{2}$ and NOX emissions $(\mathrm{kg})$ are used to better reflect the environmental impact factor.

The main connotation of hydrogen production technology is the advanced degree of technology, the hydrogen purity index reflects the advanced degree of technology, and the proportion of scientific researchers indirectly reflects the development level of high and new technology. Secondly, external dependence and technology maturity of technology are the important basis for the long-term development of China's coal enterprises $[25,26]$.

3.2. Model Construction. As a new energy source, hydrogen production technology has abundant sources of raw materials and complex hydrogen production processes. There are relatively few research studies on the development of hydrogen energy technology by coal companies. It is reasonable to plan and deploy various technologies in different periods and regions. For issues such as the order of development of hydrogen production, it is necessary to conduct an objective and scientific evaluation of various hydrogen production technologies. Therefore, the premise of the evaluation is to establish a scientific and reasonable evaluation index system. Based on the analysis of influencing factors in Section 3.1, the following comprehensive evaluation index system is established, as shown in Table 1.

\subsubsection{Standardized Processing of Indicators}

(1) Standardized Treatment of Indicators. In the comprehensive evaluation, due to the existence of different types of qualitative and quantitative indicators, or the value gap between the indicators, the original indicators affect the accuracy of the evaluation in the calculation and analysis. The presence of indicators with high numerical values has a greater impact on the whole, and the role of indicators with lower numerical levels is relatively weakened. Therefore, we need to standardize all indicators to improve the accuracy of the results. In this paper, the indicator is standardized by the extreme difference method.

(2) Consistent Processing of Indicator Types. In the comprehensive evaluation of multiple indicators, some are indicators with higher indicator values, called positive indicators, and some are indicators with smaller indicator values that evaluate the better, called reverse indicators. First of all, the indicator must be trended, generally the reverse indicator into a positive indicator, which is the consistent processing of the indicator type.

3.2.2. Comparison Based on AHP and GRA-TOPSIS. The article chooses the analytic hierarchy process to determine the weights. There are two advantages to determine the weights through the analytic hierarchy process. First, the data requirements for determining the weights through the analytic hierarchy process are relatively small, and it is relatively simple in actual operation. The indicators are analyzed systematically to improve accuracy.

In order to overcome the shortcomings of gray correlation and Technique for Order Preference by Similarity to an Ideal Solution (TOPSIS) method, this paper combines the characteristics of the two methods and integrates the two methods organically. Considering that the traditional TOPSIS method evaluates the schemes according to the Euclidean distance, sometimes it cannot fully reflect the pros and cons of the schemes, and it cannot reflect the difference between the changing trends of various factors within the sample and the ideal sample. Therefore, this paper constructs the gray correlation and TOPSIS (GRA-TOPSIS), makes full use of the characteristics of the gray correlation degree to reflect the situation change between the plan data curves and the similarity of the curve geometry, combines the Euclidean distance and the gray correlation degree, and constructs one from the two aspects of position and shape. This new relative closeness makes up for the shortcomings of the TOPSIS method. This method has clear thought, simple calculation, and strong practicability which we call it AHP and GRATOPSIS. The key calculation steps are as follows:

(1) Dimensionless procession of indicators: the data outline of each indicator is not consistent in order to eliminate the impact of the data outline and the convenience of research to standardize the data, in which the positive indicator refers to the evaluation results that play a positive role in promoting the indicators, and such indicators belong to the larger the better indicators. Conversely, negative indicators refer to indicators that play a negative role in promoting evaluation results and are among the smaller and better indicators.

Positive indicator is as follows:

$$
x_{i j}^{\prime}=\frac{x_{i j}-x_{\min }}{x_{\max }-x_{\min }} .
$$

Negative indicator is as follows:

$$
x_{i j}^{\prime}=\frac{x_{\max }-x_{i j}}{x_{\max }-x_{\min }} .
$$

(2) Build a decision matrix: $\mathrm{M}$ evaluation objects and $\mathrm{N}$ evaluation indexes are set, and the original decision matrix is $X=\left(x_{i j}\right)_{m \times n}$.

(3) Weighted normalized matrix of evaluation indicators is as follows: 
TABLE 1: Comprehensive evaluation index system of hydrogen production technology.

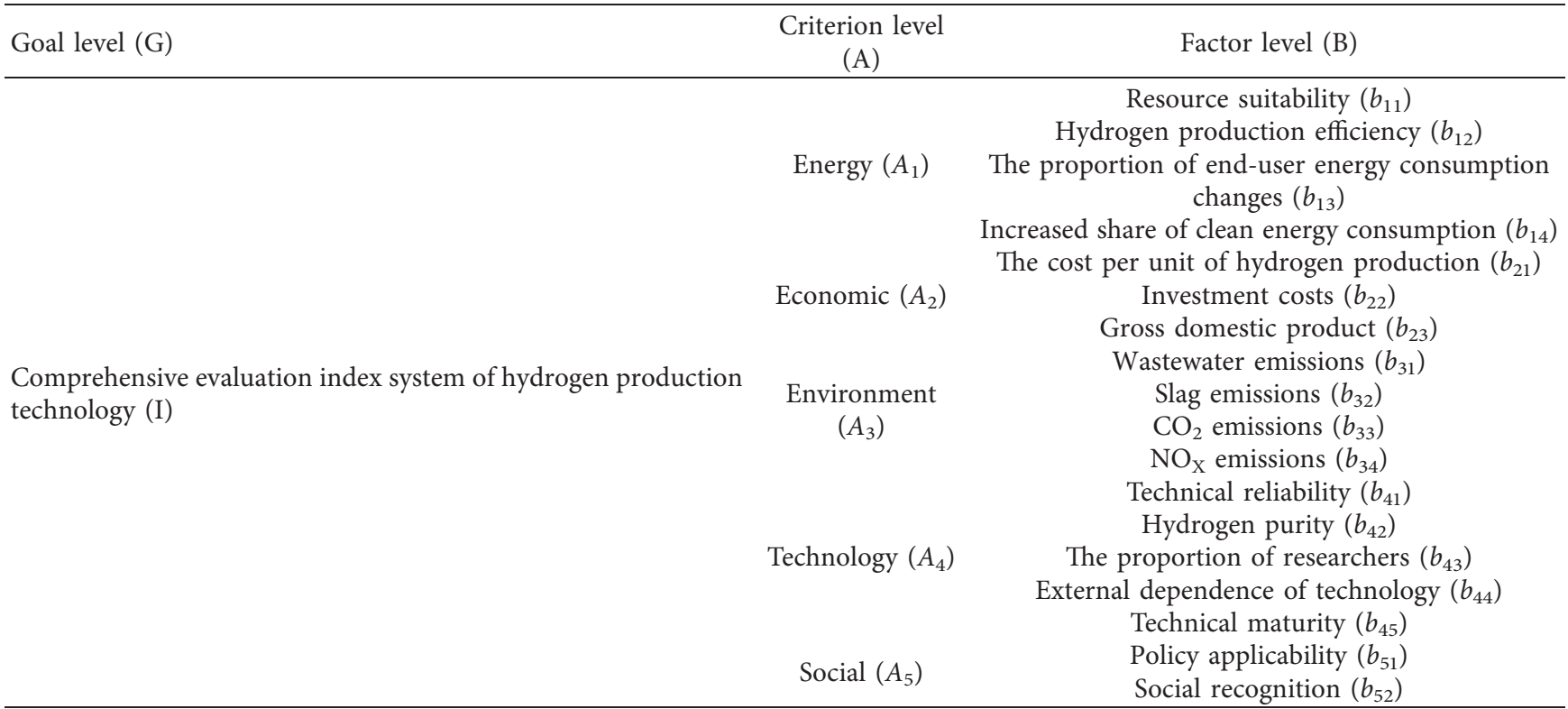

$$
\begin{aligned}
Z & =\left(\omega_{j} y_{i j}\right)_{m \times n} \\
& =\left[\begin{array}{cccc}
\omega_{1} y_{11} & \omega_{2} y_{12} & \cdots & \omega_{n} y_{1 n} \\
\omega_{1} y_{21} & \omega_{2} y_{22} & \cdots & \omega_{n} y_{2 n} \\
\vdots & \vdots & \ddots & \vdots \\
\omega_{1} y_{m 1} & \omega_{2} y_{m 2} & \cdots & \omega_{n} y_{m n}
\end{array}\right]
\end{aligned}
$$

(4) Determine the positive ideal solution and negative ideal solutions of the weighted normalization matrix:

$$
\begin{aligned}
Z^{+} & =\left(Z_{1}^{+}, Z_{2}^{+}, \ldots, Z_{n}^{+}\right) \\
& =\omega \\
Z^{-} & =\left(Z_{1}^{-}, Z_{2}^{-}, \ldots, Z_{n}^{-}\right) \\
& =0
\end{aligned}
$$

In this formula,

$$
\begin{aligned}
& Z_{j}^{+}=\max Z_{i j}=\omega_{j}, \\
& Z_{j}^{-}=\min Z_{i j}=0, \quad j \in N .
\end{aligned}
$$

(5) Calculate the Euclid distance between the schemes and the positive ideal solution and negative ideal solutions as follows:

$$
\begin{aligned}
& d_{i}^{+}=\sqrt{\sum_{j=1}^{n}\left(Z_{i j}-Z_{j}^{+}\right)^{2}} \\
& d_{i}^{-}=\sqrt{\sum_{j=1}^{n}\left(Z_{i j}-Z_{j}^{-}\right)^{2}} .
\end{aligned}
$$

(6) Calculate the gray correlation coefficient matrix between each scheme and the positive ideal solution and the negative ideal solution $R^{+}$and $R^{-}$as follows:
$R^{+}=\left(r_{i j}^{+}\right)_{m \times n}, R^{-}=\left(r_{i j}^{+}\right)_{m \times n}$

$r_{i j}^{+}=\frac{\min _{i} \min _{j}\left|z_{j}^{+}-z_{i j}\right|+\varepsilon \max _{i} \max _{j}\left|z_{j}^{+}-z_{i j}\right|}{\left|z_{j}^{+}-z_{i j}\right|+\varepsilon \max _{i} \max _{j}\left|z_{j}^{+}-z_{i j}\right|}$,

$r_{i j}^{-}=\frac{\min _{i} \min _{j}\left|z_{j}^{-}-z_{i j}\right|+\varepsilon \max _{i} \max _{j}\left|z_{j}^{-}-z_{i j}\right|}{\left|z_{j}^{-}-z_{i j}\right|+\varepsilon \max _{i} \max _{j}\left|z_{j}^{-}-z_{i j}\right|}$

In this formula, $\varepsilon \in(0,1)$ is the resolution factor, and experience is valued at 0.5 .

(7) Calculate the gray correlation between each scheme and the positive and negative ideal solutions as follows:

$$
\begin{aligned}
& r^{+}=\frac{1}{n} \sum_{j=1}^{n} r_{i j}^{+}, \\
& r^{-}=\frac{1}{n} \sum_{j=1}^{n} r_{i j}^{-} .
\end{aligned}
$$

(8) Euclid distance and correlation degree are dimensionless as follows:

$$
\begin{aligned}
& D_{i}^{+}=\frac{\mathrm{d}_{i}^{+}}{\operatorname{maxd}_{i}^{+}}, \\
& D_{i}^{-}=\frac{\mathrm{d}_{i}^{-}}{\operatorname{maxd}_{i}^{-}}, \\
& R_{i}^{+}=\frac{r_{i}^{+}}{\max r_{i}^{+}}, \\
& R_{i}^{-}=\frac{r_{i}^{-}}{\max _{i}^{-}} .
\end{aligned}
$$




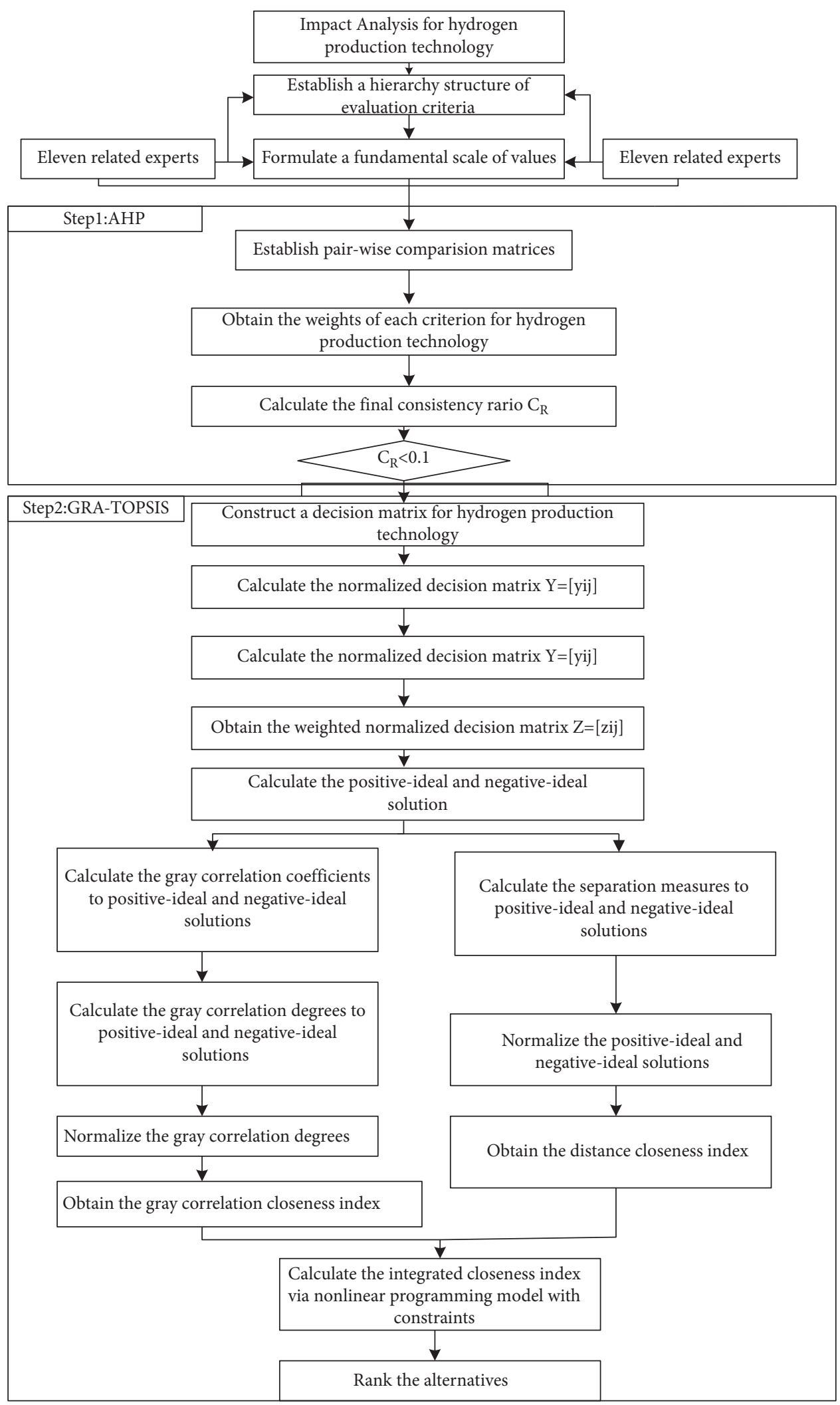

Figure 1: Model frame diagram. 
TABLE 2: Weight value of the comprehensive evaluation index of hydrogen production technology.

\begin{tabular}{|c|c|c|c|c|c|}
\hline Goal level & Criterion level (A) & Weight $\left(W_{i}\right)$ & Factor level (B) & Weight $\left(W_{i i}\right)$ & Comprehensive weights \\
\hline \multirow{18}{*}{ Comprehensive evaluation } & \multirow[t]{4}{*}{$A_{1}$} & \multirow[t]{4}{*}{0.3719} & $b_{11}$ & 0.4420 & 0.1644 \\
\hline & & & $b_{12}$ & 0.3436 & 0.1278 \\
\hline & & & $b_{13}$ & 0.0994 & 0.0370 \\
\hline & & & $b_{14}$ & 0.1150 & 0.0428 \\
\hline & \multirow[t]{3}{*}{$\mathrm{A} 2$} & \multirow[t]{3}{*}{0.1651} & $b_{21}$ & 0.7003 & 0.1156 \\
\hline & & & $b_{22}$ & 0.2230 & 0.0368 \\
\hline & & & $b_{23}$ & 0.0767 & 0.0127 \\
\hline & \multirow[t]{4}{*}{ A3 } & \multirow[t]{4}{*}{0.2854} & $b_{31}$ & 0.2014 & 0.0575 \\
\hline & & & $b_{32}$ & 0.1559 & 0.0445 \\
\hline & & & $b_{33}$ & 0.3535 & 0.1009 \\
\hline & & & $b_{34}$ & 0.2892 & 0.0825 \\
\hline & \multirow[t]{5}{*}{ A4 } & \multirow[t]{5}{*}{0.1074} & $b_{41}$ & 0.2810 & 0.0302 \\
\hline & & & $b_{42}$ & 0.2828 & 0.0304 \\
\hline & & & $b_{43}$ & 0.0693 & 0.0074 \\
\hline & & & $b_{44}$ & 0.0903 & 0.0097 \\
\hline & & & $b_{45}$ & 0.2766 & 0.0297 \\
\hline & \multirow[t]{2}{*}{ A5 } & \multirow[t]{2}{*}{0.0703} & $b_{51}$ & 0.6562 & 0.0461 \\
\hline & & & $b_{52}$ & 0.3438 & 0.0242 \\
\hline
\end{tabular}

TABLE 3: Dimensionless processing results.

\begin{tabular}{lcccc}
\hline Scheme & $D_{i}^{+}$ & $D_{i}^{-}$ & $R_{i}^{+}$ & $R_{i}^{-}$ \\
\hline Coal gasification & 0.9241 & 0.8306 & 0.9975 & 0.8807 \\
Coke oven gas & 0.5057 & 1.0000 & 1.0000 & 0.8696 \\
Electrolytic water & 1.0000 & 0.9589 & 0.9255 & 1.0000 \\
Solar & 0.8778 & 0.8331 & 0.9615 & 0.9229 \\
\hline
\end{tabular}

TABLE 4: Comparison with AHP-TOPSIS and AHP-GC.

\begin{tabular}{lccc}
\hline Scheme & AHP-TOPSIS & AHP-GC & AHP-GC\&TOPSIS \\
\hline Coal gasification & 0.473357269 & 0.4689064 & 0.5032 \\
Coke oven gas & 0.664142924 & 0.46512623 & 0.5925 \\
Electrolytic water & 0.489509419 & 0.51934562 & 0.4851 \\
Solar & 0.4869367 & 0.48975801 & 0.4992 \\
\hline
\end{tabular}

TABLE 5: Comprehensive evaluation and ranking table of hydrogen production technical scheme.

\begin{tabular}{|c|c|c|c|c|}
\hline Scheme & $P_{i}^{+}$ & $P_{i}^{-}$ & Relative closeness & Rank \\
\hline Coal gasification & 0.9140 & 0.9024 & 0.5032 & 2 \\
\hline Coke oven gas & 1.0000 & 0.6877 & 0.5925 & 1 \\
\hline Electrolytic water & 0.9422 & 1.0000 & 0.4851 & 4 \\
\hline Solar & 0.8973 & 0.9004 & 0.4992 & 3 \\
\hline
\end{tabular}

(9) Combine dimensionless distance and correlation degree. The greater the $D_{i}^{-}$and $R_{i}^{+}$is, the closer the scheme is to the positive ideal solution. The larger the $D_{i}^{+}$and $R_{i}^{-}$is, the farther away the scheme is from the positive ideal solution. Therefore, the combination formula can be determined as follows:

$$
P_{i}^{+}=\alpha D^{-}+\beta R^{+}, P_{i}^{-}=\alpha D^{+}+\beta R^{-} .
$$

In this formula, $\alpha=\beta=1 / 2$.

(10) Relative closeness of the construction scheme is as follows:

$$
Q_{i}^{+}=\frac{P_{i}^{+}}{P_{i}^{+}+P_{i}^{-}} .
$$

(11) The relative closeness degree $Q_{i}^{+}$of each scheme was calculated and ranked. The greater the relative closeness degree was, the closer it was to 1 , indicating the higher the evaluation of the scheme was. On the contrary, the lower the relative closeness, the worse the scheme.

In order to explain the model more intuitively, the model frame diagram is shown as follows (see Figure 1). 


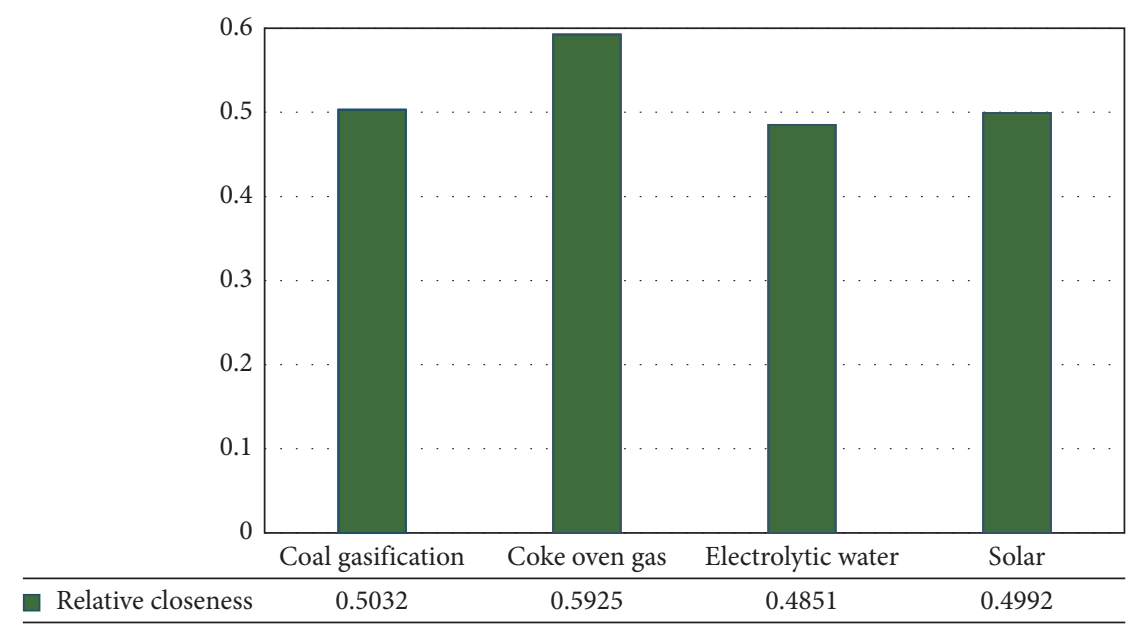

FIGURE 2: Relative closeness of comprehensive evaluation of hydrogen production technology.

\section{Application}

In this section, the use of AHP and Gray Correlation Ideal Solution is illustrated by evaluating the hydrogen production technologies in a certain mining group. The mining group is a modern enterprise group that spans regions and industries. It is actively exploring the application of hydrogen purification and storage technology and the industrial production of hydrogen fuel cells.

4.1. Data Collection. The data and related information come from enterprises such as experts, scholars, and university experts with professional knowledge and management experience. Through the questionnaires collected in this study, 11 experts were consulted, and the comparison matrix for each standard was matched and used to evaluate the decision matrix hydrogen production technology. The four alternatives can make the evaluation results more in line with the development of the mining group.

\subsection{Hierarchical Structure of Hydrogen Production Technol-} ogies Evaluation. Based on the related literature and expert interview, five kinds of dimensions and their parameters have been given. We establish a hierarchical structure for their comprehensive evaluation, which is shown in Table 2.

4.3. Comprehensive Evaluation Based on Gray CorrelationTOPSIS Method. According to the formula, the gray association between each scheme and the positive and negative ideal solution is calculated as follows:

$$
\begin{aligned}
& r^{+}=\left[\begin{array}{lllll}
0.8436 & 0.8458 & 0.7828 & 0.8132
\end{array}\right], \\
& r^{-}=\left[\begin{array}{llll}
0.7555 & 0.7459 & 0.8578 & 0.7917
\end{array}\right] \text {. }
\end{aligned}
$$

Euclid distance and gray relational degree were dimensionless and were obtained $D_{i}^{+}, D_{i}^{-}$and $R_{i}^{+}, R_{i}^{-}$. The results are shown in Table 3.
According to formula (10), scale distance and correlation degree will not be combined. Finally, according to formula (11), the relative proximity of the hydrogen scheme samples is constructed, and according to the size of the relative schedule, the samples are sorted; the closer the proximity 1 , the better the scheme.

4.4. Results and Analysis. In this paper, the AHP-TOPSIS method and AHP-GC method are used to compare the results of the proposed methods. The weight of each influencing factor adopted by the three methods is the same. The closeness index results of the three methods are shown in Table 4 .

It can be seen from Table 4 that the results of the three methods are basically consistent and close, which shows that the proposed AGT is reasonable and feasible to evaluate the performance of the design scheme. Because the gray closeness index of Option 1 and Option 2 is similar, AHPGC cannot determine the best solution between Option 1 and Option 3, and AGT can do this. In other words, the result of AGT is a comprehensive evaluation value of AHPTOPSIS and AHP-GC. When evaluating the performance of the design plan, a mixed feature involving positional relationship and situation changes between data sequences is used. Therefore, the AGT method overcomes the one-sidedness of the AHP-TOPSIS and AHP-GC methods and makes the evaluation results more objective and true.

Through the previous evaluation and research on various hydrogen production technologies, the ranking of the comprehensive evaluation of various hydrogen production technologies has been obtained. Now, the research results are further analyzed, and the ranking is as shown in Table 5.

It can be seen from Figure 2 that coke oven gas hydrogen production is the most closely related hydrogen production technology, with a closeness of 0.5925 , indicating that coke oven gas hydrogen production is the preferred hydrogen production technology for a mining group's transformation and development of hydrogen energy. On the one hand, because coke oven gas is compared with the traditional hydrogen production method, 
hydrogen extraction is not only a more environmentally friendly comprehensive utilization of resources but also has very considerable economic benefits; on the other hand, in the example, coal enterprises are the mainstay, and the output of coke oven gas is abundant. Through reasonable purification technology, hydrogen energy can be produced on a large scale, compared with electrolysis of water to produce hydrogen, and the cost is low. The second in the ranking of relative closeness is the traditional coal gasification hydrogen production, which has already been produced on a large scale in China, with relatively mature technology and low cost, but there are also problems such as high carbon emissions and many gas impurities. The hydrogen production technology ranked last is hydrogen production by electrolysis of water, with a relative closeness of 0.4851 .

\section{Conclusions}

This paper takes coal gasification hydrogen production, coke oven gas hydrogen production, electrolysis water hydrogen production, and solar hydrogen production as the research objects and conducts a multidimensional comprehensive evaluation by constructing a multilevel comprehensive evaluation index system. At the same time, the model was verified based on the actual situation of a certain mining group, and the following conclusions were drawn.

The GRA-TOPSIS method is used to construct a comprehensive evaluation model of hydrogen production technology. By combining Euclidean distance and gray correlation, a new relative closeness is constructed from two aspects of position and shape, which can make up for the respective defects of GRA and TOPSIS; through calculations according to the comprehensive closeness of various hydrogen production technologies, the comprehensive closeness of coke oven gas hydrogen production technology is the highest, which is the most suitable hydrogen production technology choice for a certain mining group's hydrogen energy development, followed by coal gasification hydrogen production technology; this model can provide a certain theoretical basis for coal enterprises to select hydrogen production technology as a breakthrough point for transformation.

There are still some shortcomings in the research of this paper, and future research can be further deepened and broadened. In this research, the qualitative indicators are quantified by the expert scoring method and the range method. However, with the improvement of national policies and the development of hydrogen production technology, related cognition and data will also change. A more scientific and comprehensive evaluation model is still needed to adapt to future development; as currently emerging hydrogen production technologies such as biomass hydrogen production have certain difficulties in data collection, with the deepening of relevant research, a more comprehensive approach can be considered. Other emerging hydrogen production technologies could be included in the research object.

\section{Data Availability}

The data that support the findings of this study are available from the corresponding author, Kangdi Yang, upon reasonable request.

\section{Disclosure}

To make the research open and transparent, a preprinted version of this manuscript was placed in Research Square [27]. The authors have cited this version in the last and hope to update its link.

\section{Conflicts of Interest}

The authors declare that there are no conflicts of interest.

\section{Acknowledgments}

The authors wish to acknowledge financial support from the National Key Research and Development Plan (Grant no. 2017YFC1503103).

\section{References}

[1] R. Ding, X. Zhou, R. Zhang, and W. Lu, "Research on the measurement and countermeasure of coal overcapacity in China: based on panel data of 25 provinces in China," Energy Engineering, vol. 117, no. 1, pp. 27-39, 2020.

[2] C. Dga, A. Fb, B. Ds, C. Mdb, A. Nw, and A. \&Rg, "The role of renewable energy in the global energy transformation-sciencedirect," Energy Strategy Reviews, vol. 24, pp. 38-50, 2019.

[3] D. Parra and L. Valverde, F. J. Prino and K Martin, "A review on the role, cost and value of hydrogen energy systems for deep decarbonisation," Renewable \& Sustainable Energy Reviews, vol. 101, pp. 279-294, 2019.

[4] The Central People's Government of the People's Republic of China, "The Fourteenth Five-Year Plan for the National Economic and Social Development of the People's Republic of China and the Outline of the Long-Term Goals for 2035," 2021, http://www.gov.cn/xinwen/2021-03/13/content_ 5592681.htm.

[5] J. L. Silveira, Sustainable Hydrogen Production Processes, Springer, Berlin, Germany, 2017.

[6] M. El-Shafie, S. Kambara, and Y. Hayakawa, "Hydrogen production technologies overview," Journal of Power and Energy Engineering, vol. 7, no. 1, pp. 107-154, 2019.

[7] N. Saithong, S. Authayanun, Y. Patcharavorachot, and A. Arpornwichanop, "Thermodynamic analysis of the novel chemical looping process for two-grade hydrogen production with co2 capture," Energy Conversion and Management, vol. 180, pp. 325-337, 2019.

[8] S. Chai, G. Zhang, G. Li, and Y. Zhang, "Industrial hydrogen production technology and development status in China: a review," Clean Technologies and Environmental Policy, vol. 23, no. 7, pp. 1931-1946, 2021.

[9] A. X. Y. Mah, W. S. Ho, C. P. C. Bong et al., "Review of hydrogen economy in Malaysia and its way forward," International Journal of Hydrogen Energy, vol. 44, no. 12, pp. 5661-5675, 2019.

[10] J. Wang, W. Wei, and J. Zhang, "Theoretical description of drawing body shape in an inclined seam with longwall top 
coal caving mining," International Journal of Coal Science \& Technology, vol. 7, no. 1, pp. 182-195, 2020.

[11] J. Wang, S. Yang, W. Wei, J. Zhang, and Z. Song, "Drawing mechanisms for top coal in longwall top coal caving (LTCC): a review of two decades of literature," International Journal of Coal Science \& Technology, 2021.

[12] H. Wu, D. Ma, A. J. S. Spearing, and GuoyanZhao, "Fracture phenomena and mechanisms of brittle rock with different numbers of openings under uniaxial loading," Geomechanics and Engineering, vol. 25, no. 6, pp. 481-493, 2021.

[13] Y. Y. Zhang, Research on the Carbon Emissions of Modern Coal Chemical Industry and its Economic Impact (PhD Dissertation, China University of Mining and Technology, Xuzhou. Beijing, China, 2017, https://kns.cnki.net/KCMS/detail/detail.aspx? dbname $=$ CDFDLAST2018\&filename $=1017237807$.

[14] B. Hu and Y. J. Han, "Modeling of technical and economic evaluation of coal upstream industrial chain projects," Coal Economic Research, vol. 36, no. 5, pp. 49-54, 2016.

[15] T. L. Saaty, "How to make a decision: the analytic hierarchy process," European Journal of Operational Research, vol. 48, no. 1, pp. 9-26, 1994.

[16] C.-T. Chen, "Extensions of the topsis for group decisionmaking under fuzzy environment," Fuzzy Sets and Systems, vol. 114, no. 1, pp. 1-9, 2000.

[17] S. Prince-Richard, M. Whale, and N. Djilali, "A technoeconomic analysis of decentralized electrolytic hydrogen production for fuel cell vehicles," International Journal of Hydrogen Energy, vol. 30, no. 11, pp. 1159-1179, 2005.

[18] P. Konstantopoulou, D. Giannopoulos, and M. \&Founti, "Multicriteria analysis of hydrogen production technologies," in Proceedings of the International Hydrogen Energy congress and Exhibition IHEC, Ankara, Turkey, July 2005.

[19] Y. Li, "Several Hydrogen Production Methods of Life Cycle Assessment Studies," Master's Degree Thesis, xian building university of science and technology, Hefei, China, 2010.

[20] B. Luo, Y. Zhou, B. Yu, R. Xiao, and C. Yang, "Comparison of chemical and biological hydrogen production processes," Ceramic, vol. 12, no. 1, pp. 23-28, 2019, https://www.energy. gov/eere/fuelcells/hydrogen-production-processes.

[21] XieXinshuo, W. Yang, W. Shi, S. Zhang, Z.\& Wang, and J. Zhou, "Progress in life cycle assessment of hydrogen production technology," Chemical Industry Progress, vol. 37, no. 6, pp. 2147-2158, 2018.

[22] J. Niu, "Study on System Evaluation System of Hydrogen Production Technology," Master Thesis, Beijing University of Chemical Technology, Beijing, China, 2007.

[23] Y.-J. Xing, T.-L. Chen, M.-Y. Gao, S.-L. Pei, W.-B. Pan, and P.-C. Chiang, "Comprehensive performance evaluation of green infrastructure practices for urban watersheds using an engineering-environmental-economic (3E) model," Sustainability, vol. 13, no. 9, p. 4678, 2021.

[24] M. Dai, F. Yang, Z. Zhang, G. Liu, and X. Feng, "Energetic, economic and environmental (3E) multi-objective optimization of the back-end separation of ethylene plant based on adaptive surrogate model," Journal of Cleaner Production, vol. 310, Article ID 127426, 2021.

[25] D. Z. Kong, S. J. Pu, Z. H. Cheng, G. Y. Wu, and Y. Liu, "Coordinated deformation mechanism of the top coal and filling body of gob-side entry retaining in a fully mechanized caving face," International Journal of Geomechanics, vol. 21, no. $4,2021$.

[26] F. Wen, "The Fuel Cell Car Hydrogen System Evaluation and Case Study of Beijing," A Master's Degree Thesis, tsinghua university, Beijing, China, 2003.
[27] S. Zhong and K. Yang, "Comprehensive Evaluation of Hydrogen Production from Coal Base on AHP\& GRA-TOPSIS," 06 May 2021, https://assets.researchsquare.com/files/rs480265/v1_covered.pdf?c=1631865863. 